\title{
The use of desoxycorticosterone pivalate in dogs with hypoadrenocorticism: a retrospective study of eight cases
}

\author{
Het gebruik van desoxycorticosterone-pivalaat bij honden met hypoadrenocorticisme: \\ een retrospectieve studie van acht gevallen
}

\author{
M. Albers, P. Defauw, F. Mortier, S. Daminet
}

Small Animal Department

Faculty of Veterinary Medicine, Ghent University

Salisburylaan 133, B-9820 Merelbeke, Belgium

maai.albers@hotmail.com

\section{$\Lambda_{\text {bstract }}$}

In this article, the use of desoxycorticosterone pivalate is retrospectively reviewed in eight dogs with primary hypoadrenocorticism, presented at the Small Animal Department of Ghent University. The results showed that desoxycorticosterone pivalate provided adequate mineralocorticoid replacement in all cases, also in the dogs that had previously been treated with fludrocortisone acetate. A starting dosage of $1.5-2.2 \mathrm{mg} / \mathrm{kg} \mathrm{SC}$ was used, with a fixed dosing interval of 28 days in most of the cases. Each time, prednisolone was added to the therapy as glucocorticoid supplementation. No side effects related to desoxycorticosterone pivalate therapy were noted and all owners were satisfied with the treatment consisting of desoxycorticosterone pivalate and prednisolone.

\section{SAMENVATTING}

In deze retrospectieve studie wordt het gebruik van desoxycorticosterone-pivalaat beschreven bij acht honden met primair hypoadrenocorticisme die aangeboden werden op de vakgroep Kleine Huisdieren (Faculteit Diergeneeskunde, UGent). Uit de resultaten bleek dat desoxycorticosteronepivalaat adequaat was voor de supplementatie van mineralocorticoïden in alle gevallen, ook bij de honden die voordien behandeld werden met fludrocortisone-acetaat. Een aanvangsdosis van 1,5 - 2,2 $\mathrm{mg} / \mathrm{kg} \mathrm{SC}$ werd gegeven met een vast doseringsinterval van 28 dagen in de meeste gevallen. Ter supplementatie van de glucocorticoïden werd aan de behandeling telkens prednisolone toegevoegd. Er werden geen bijwerkingen gezien die aan desoxycorticosterone-pivalaat konden worden toegeschreven en de eigenaren van de honden waren allen tevreden over de behandeling met desoxycorticosteronepivalaat en prednisolone.

\section{INTRODUCTION}

Canine hypoadrenocorticism (HA), also known as Addison's disease, is an uncommon endocrine disease with an overall prevalence of 0.13 to $0.5 \%$, and with a higher prevalence in certain breeds (Reusch, 2000; Feldman and Nelson, 2004; Hanson et al., 2016). The majority of dogs with HA have primary HA, most often caused by an immune-mediated lymphocytic adrenalitis, resulting in both glucocorticoid (GC) and mineralocorticoid (MC) deficiencies (Peterson et al., 1996; Feldman and Nelson, 2004). There are no pathognomonic signs for HA. Usually, dogs pres- ent with a variety of non-specific, waxing and waning signs. Most often, these are gastrointestinal in origin, such as anorexia, vomiting and diarrhea, sometimes with associated blood loss. However, as the disease progresses, dogs can present in circulatory shock, i.e. acute Addisonian crisis. Azotemia and non-regenerative anemia are often noted, although an absent or reversed stress leukogram and hyperkalemia, often combined with hyponatremia, are more important features. A low sodium-to-potassium ratio of less than 27 to 1 is more specific. These findings, especially the abnormal serum electrolyte levels, can raise the suspicion of HA. However, an adrenocorticotropic hor- 
mone (ACTH) stimulation test remains mandatory to confirm the diagnosis. Serum cortisol concentrations below $2 \mathrm{mcg} / \mathrm{dL}$ or $50 \mathrm{nmol} / \mathrm{L}$ before and one hour after ACTH administration are diagnostic (Peterson et al., 1996; Feldman and Nelson, 2004; Klein and Peterson, 2010a; Lathan and Thompson, 2018).

Short-term treatment of dogs with an Addisonian crisis includes aggressive intravenous fluid therapy with $0.9 \%$ saline and the administration of GC. If available, short-acting $\mathrm{MC}$ are given as well. Longterm treatment requires lifelong replacement of deficient MC and GC hormones. Fludrocortisone acetate (FC), a potent synthetic MC formulation with some GC activity, can be used orally at a starting dosage of $0.01 \mathrm{mg} / \mathrm{kg}$ twice daily (Feldman and Nelson, 2004; Meeking, 2007; Klein and Peterson, 2010b; Lathan and Thompson, 2018). Since 2016, desoxycorticosterone pivalate (DOCP) has been registered for the treatment of canine HA in most European countries by Dechra Pharmaceuticals (Zycortal ${ }^{\circledR}$, United Kingdom). As DOCP only has MC activity, prednisolone must be administered daily. A starting dosage of DOCP of $2.2 \mathrm{mg} / \mathrm{kg}$ SC every 25 days is suggested by the manufacturer and has been reported by Feldman and Nelson (2004). Bates et al. (2013) and Lathan and Thompson (2018) have recently proven that lower dosages and longer dosing intervals of DOCP are effective as well. Likewise, at the Post Congress day of the European Society of Veterinary Endocrinology (ESVE) in Göteborg (2016), it has been suggested to use lower dosages at a fixed time interval of 28 days. According to Feldman and Nelson (2004), Klein and Peterson (2010b) and Lathan and Thomspon (2018), follow-up with a physical examination and the measurement of serum electrolyte concentrations should be performed 10 days and 25 days post injection, in order to determine the need for adjustment of the dosage and/or dosing interval. If potassium levels are high and/or sodium levels low at day 10 , the dose of DOCP should be increased by $5-15 \%$, whereas the dosage interval can be decreased by $1-2$ days if this is noted at day 25 (or 28). If the potassium levels are low and/or sodium levels high at day 10 , a dose reduction of $5-15 \%$ should be performed, and if noted at day 25 (or 28) the dosage interval can be prolonged by 1 - 2 days. This should be carried out until achieving stabilization of the DOCP dosage (Klein and Peterson, 2010b; Lathan and Thompson, 2018). Once the adequate dose and interval have been determined, the patient should be monitored twice a year with a physical examination and serum electrolyte measurement (Feldman and Nelson, 2004; Klein and Peterson, 2010b; Lathan and Thomspon, 2018). With appropriate treatment, prognosis is excellent, with normal quality of life and life expectancy in more than $80 \%$ of the treated dogs. However, timely diagnosis and treatment are important, as a lacking diagnosis can result in a fatal Addisonian crisis (Van Zyl and Hyman, 1994; Meeking, 2007; Klein and Peterson, 2010b; Lathan and Thompson, 2018).

\section{MATERIALS AND METHODS}

\section{Case selection}

Medical records of all dogs diagnosed with primary HA and treated with DOCP (Zycortal ${ }^{\circledR}$, Dechra Veterinary Products NV, Lille, Belgium) at the Small Animal Department of the Faculty of Veterinary Medicine (Ghent University) between January 2016 and September 2017 were reviewed retrospectively. These included both newly diagnosed cases and cases that were previously treated with FC. Dogs were excluded if follow-up, including electrolyte measurement, was not available for at least one month.

\section{Procedures}

Signalment, history, physical examination, serum electrolyte concentrations, side effects of and response to therapy were extracted from the medical files. A standardized questionnaire was used to evaluate the owner's opinion concerning costs, number of control visits and blood draws, as well as the clinical condition of their dog during the treatment with DOCP and prednisolone.

\section{Objectives}

The objective of this retrospective study was to give a detailed description of the use of DOCP in a series of dogs with primary HA.

\section{RESULTS}

\section{Signalment}

The median age at presentation was four years (range 1 - 9 years). Five out of the eight dogs were male. All but one were pedigree dogs, of the following breeds: bearded collie, papillon, English cocker spaniel, Leonberger, standard poodle, Shih Tzu and Irish terrier.

\section{History, clinical signs and physical examination at initial presentation}

Six dogs had been newly diagnosed, of which five were emergency cases, presented with an acute Addisonian crisis. Of these five dogs, one dog presented with signs of hypovolemic shock, with severe hypotension and stupor, while the other four expressed signs of dehydration. Five newly diagnosed cases presented with acute lethargy and anorexia, although this was chronic in one new case. Vomiting was noted in four of them and polyuria/polydipsia was present in three cases. Three of these five dogs also had chronic and intermittent complaints, namely lethargy, intermittent anorexia, episodic vomiting and diarrhea or polyuria/ polydipsia. The remaining two cases had been receiv- 
ing $\mathrm{GC}$ and $\mathrm{FC}$ before presentation. Both dogs were monitored with frequent clinical controls and measurement of serum electrolyte concentrations. Both were switched to GC and DOCP due to insufficient control of the disease, manifested by vomiting, anorexia and lethargy in one case and persistent GC side effects (polyuria/polydipsia, polyphagia and/or poor skin condition) with abnormal electrolyte levels in both cases.

\section{Laboratory findings at initial presentation}

One dog showed mild regenerative anemia and all dogs had an absent or reversed stress leukogram. Five dogs had elevated levels of serum urea, of which one showed mild azotemia and two more pronounced azotemia. One dog was severely hypoglycemic and one dog presented with mild hyperalbuminemia. All dogs had abnormal serum electrolyte levels, six of which showed hyperkalemia and seven hyponatremia. In half of the cases, the electrolyte abnormalities were severe, with potassium values above $7 \mathrm{mmol} / 1$ in four and sodium levels below $125 \mathrm{mmol} / \mathrm{l}$ in one case (reference intervals 3.5 - 5.8 and $144-160 \mathrm{mmol} / 1$, respectively).

\section{Treatment}

\section{Stabilization and initial treatment with DOCP and prednisolone}

Both dogs previously treated with $\mathrm{FC}$ and one other dog were not hospitalized at the time of the first DOCP injection. The other five dogs that suffered from an Addisonian crisis, were initially stabilized with adequate fluid therapy, using $0.9 \%$ saline. In four cases, IV boli of glucose $50 \%$ at $0.5-2 \mathrm{~g} / \mathrm{kg}$ (Glucose Sterop $50 \mathrm{mg} / \mathrm{ml}$, Laboratories Sterop, Brussels, Belgium) and in three dogs, short-acting human insulin at $0.1 \mathrm{IU} / \mathrm{kg}$ (Humuline Regular Cartridge $100 \mathrm{IU} / \mathrm{ml}$, Eli Lilly Benelux NV, Brussels, Belgium) were administered. As a result, three of the hospitalized dogs had normal electrolyte levels at the time of DOCP administration, one still had slight abnormalities and in one case, it was not remeasured. The starting dosage of $2.2 \mathrm{mg} / \mathrm{kg} \mathrm{SC}$, as prescribed by the manufacturer, was given to six dogs, while two dogs received a lower starting dosage of $1.5 \mathrm{mg} / \mathrm{kg} \mathrm{SC}$. All dogs had normal serum electrolyte levels ten days after the DOCP injection, although one dog showed borderline hyperkalemia. Prednisolone was also administered to all dogs, at a dosage of $0.11-0.5 \mathrm{mg} / \mathrm{kg} /$ day PO, which in all but two cases was divided over two gifts. Both dogs that were switched to DOCP, had a doubling of the previously given dosage of prednisolone. Clinical signs resolved in all dogs within ten days.

\section{Second injection with DOCP}

From the six dogs that were started on $2.2 \mathrm{mg} / \mathrm{kg}$ DOCP, three had a subsequent $10 \%$ decrease in DOCP dosage, while a larger dose reduction of $20 \%$ was performed in the two other dogs. According to the guidelines of the manufacturer (Table 1), this reduction was based on the sodium:potassium ratio, which was approximately 34 in the first three cases and significantly higher in the last two cases. Therefore, it was opted to implement an even higher dose reduction in these two cases. The last dog (previously treated with FC) was kept on the same starting dosage of $2.2 \mathrm{mg} / \mathrm{kg}$, but the dosage interval was increased based on serial electrolyte measurements. A fixed interval rate of 64 days was eventually achieved in this dog. Two other dogs were started on $1.5 \mathrm{mg} / \mathrm{kg}$. One of these dogs had a dose reduction of $10 \%$. The other dog (also previously treated with FC) needed an increase of $10 \%$, due to borderline hyperkalemia at day ten post injection.

\section{Further follow-up}

Long-term follow-up was available in four dogs. For three of those dogs, the maintenance dosage of DOCP varied between $1.2-1.8 \mathrm{mg} / \mathrm{kg}$ every 28 days. The maintenance dosage was reached after two dosage adjustments of DOCP in these dogs. For the dog, for which interval prolongation was chosen above dose reduction, the dosage remained $2.2 \mathrm{mg} / \mathrm{kg}$ with a fixed extended interval of 64 days. The maintenance dosage for prednisolone was $0.08-0.28 \mathrm{mg} / \mathrm{kg} / \mathrm{d} \mathrm{PO}$, given once daily in all but one case.

\section{Owner satisfaction and side effects during treatment}

There was a high owner satisfaction rate for the treatment of HA with DOCP and prednisolone, based on a scale ranging from unsatisfied to very satis-

Table 1. Guidelines for dosage adjustment of Zycortal ${ }^{\circledR}$ according to the manufacturer (Dechra Veterinary Products, United Kingdom). Administering the second dose of Zycortal Suspension.

\begin{tabular}{lll}
$\begin{array}{l}\text { If the day } \mathbf{1 0} \\
\mathbf{N a}^{+} / \mathbf{K}^{+} \text {ratio is: }\end{array}$ & $\begin{array}{l}\mathbf{2 5} \text { days after the first dose, administer } \\
\text { Zycortal suspension, as follows: }\end{array}$ \\
\hline$>34$ & Do not & Decrease dose to: $2.0 \mathrm{mg} / \mathrm{kg}$ \\
$>32$ to 34 & administer & Decrease dose to: $2.1 \mathrm{mg} / \mathrm{kg}$ \\
27 to 32 & dose 2 & Continue $2.2 \mathrm{mg} / \mathrm{kg}$ \\
24 to $<27$ & on day 10 & Increase dose to: $2.3 \mathrm{mg} / \mathrm{kg}$ \\
$<24$ & & Increase dose to: $2.4 \mathrm{mg} / \mathrm{kg}$ \\
\hline
\end{tabular}


fied, with seven owners being very satisfied and one satisfied. For the owners of the two dogs that were switched from FC to DOCP, the satisfaction rate was notably higher than during the treatment with FC. Two dogs, which were immediately started on DOCP, experienced polyuria/polydipsia during the treatment with DOCP and prednisolone, which resolved after a reduction of the prednisolone dose. No adverse effects attributable to DOCP were noted.

\section{DISCUSSION}

Pure bred, young to middle-aged dogs were overrepresented in this case series, although two dogs were older. A female predisposition was not observed in the present cases, in contrast to the literature, in which a predisposition of $69 \%$ has been stated (Feldman and Nelson, 2004). This could be due to the small number of cases in this retrospective study.

Most of the cases (63\%) were presented as an emergency, which could be explained by the dogs being selected from a referral university clinic. Most dogs (also 63\%) showed gastrointestinal signs, and all of them presented with anorexia and lethargy, which is consistent with the literature. The clinical signs can be attributed to the lack of GC, which are vital for maintaining the mucosal gastric barrier, blood pressure, blood glucose and body temperature and for stress counterregulation. The lack of MC also contributes to clinical signs, as they play a role in water homeostasis by promoting renal sodium resorption and potassium excretion (Meeking, 2007; Klein and Peterson, 2010a; Lathan and Thomspon, 2018).

Only one dog showed mild regenerative anemia, which was most likely due to gastrointestinal bleeding since high urea levels were also present. Dehydration could have falsely elevated the levels of packed cell volume in other cases, masking anemia. The presence of dehydration was also evident based on hyperalbuminemia in one dog. Dehydration and/or gastrointestinal bleeding could explain the high percentage of dogs with increased urea. One dog had unmeasurably low blood glucose levels, which could be attributed to the lack in GC causing decreased hepatic gluconeogenesis and increased insulin sensitivity, combined with the anorexia and vomiting in a toy breed dog (Feldman and Nelson, 2004; Klein and Peterson, 2010a; Lathan and Thompson, 2018).

All dogs showed abnormal serum electrolyte concentrations, which is mainly caused by the lack of MC. As described in the literature, serum levels of sodium and potassium normalized in most of the present cases (7/8) within 24 hours after initiating fluid therapy (Feldman and Nelson, 2004; Klein and Peterson, 2010b; Lathan and Thompson, 2018).

The first dog being treated with DOCP followed the protocol suggested by the manufacturer (Table 1). A starting dosage of $2.2 \mathrm{mg} / \mathrm{kg} \mathrm{SC}$ was administered and the dog was then monitored at day 10, day 25 and every five days thereafter until the sodium-to-potassium ratio dropped beneath 32 , eventually resulting in a fixed interval of 64 days. Gaining experience with DOCP, following new guidelines that were discussed at the ESVE Post-Congress day, and considering the recent literature, all following dogs had a fixed interval of 28 days and two dogs were treated with a lower starting dosage of $1.5 \mathrm{mg} / \mathrm{kg}$ SC (Bates et al., 2013; Lathan and Thompson, 2018). However, one of these dogs needed an increase of the dosage at the time of the second injection of DOCP. Due to sodium-to-potassium ratios being markedly higher than 34 , a dose reduction of $20 \%$ was performed in two other dogs, which is a larger dose reduction than the $5-15 \%$ dose reduction suggested in the literature (Klein and Peterson, 2010b; Lathan and Thomspon, 2018). For both dogs that were switched from FC to DOCP, FC was immediately stopped after injection with DOCP, but with a doubling of the previously administered prednisolone dosage. Both dogs were switched to DOCP due to insufficient control of the serum electrolyte concentrations with FC, whilst already expressing $\mathrm{GC}$ side effects. After the switch to DOCP, the serum electrolyte concentrations normalized rapidly and the GC side effects disappeared or improved greatly. Baumstark et al. (2014) suggested that DOCP is more effective than FC in the treatment of HA. However, an earlierer study of Kintzer and Peterson (1997) with 205 dogs showed no difference regarding efficacy of MC replacement and survival time between DOCP and FC.

The starting dosage of prednisolone was notably lower in two cases and higher in one case, than the dosage of $0.22-0.3 \mathrm{mg} / \mathrm{kg} /$ day reported in the literature. However, the two dogs receiving a lower dosage were previously treated with FC and GC before the first administration of DOCP. In most cases $(75 \%)$, the maintenance dosage of prednisolone was lower than the dosage of $0.2 \mathrm{mg} / \mathrm{kg} /$ day reported in the literature (Van Zyl and Hyman, 1994; Kintzer and Peterson, 1997; Reusch, 2000; Klein and Peterson, 2010b), although a similar dosage has recently been described (Lathan and Thompson, 2018).

It should be mentioned that the main limitations of this study were the relatively small number of dogs and all limitations inherent to the retrospective nature of this study.

\section{CONCLUSION}

In conclusion, DOCP was successful in maintaining normal serum electrolyte concentrations in eight dogs with HA, both in newly diagnosed cases and in dogs previously treated with FC. A fixed dosage interval of 28 days was deemed effective and practical. A dose reduction of DOCP was possible in $75 \%$ of the cases at the time of the second injection. In one out of 
the two cases treated with a lower starting dosage (1.5 $\mathrm{mg} / \mathrm{kg}$ ), treatment was effective; however, an increase in DOCP dosage was necessary for the dog that was previously treated with FC.

\section{REFERENCES}

Bates J., Shott S., Schall W. (2013). Lower initial dose desoxyccorticosterone pivalate for treatment of canine primary hypoadrenocorticism. Australian Veterinary Journal 91, 77-82.

Baumstark M.E., Nussberger J., Boretti F., Baumstark M.W., Riond B., Reusch C., Sieber-Ruckstuhl N. (2014). Use of plasma renin activity to monitor mineralocorticoid treatment in dogs with primary hypoadrenocorticism: desoxycorticosterone versus fludrocortisone. Journal of Veterinary Internal Medicine 28, 1471-1478.

Feldman E. , Nelson R. (2004). Hypoadrenocorticism (Addison's Disease). Canine and Feline Endocrinology and Reproduction. Third edition, WB Saunders, St. Louis, 394-439.

Hanson J., Tengvall K., Bonnett B., Hedhammar A. (2016). Naturallly occurring adrenocortical insufficieny - An epidemiological study based on a Swedish-insured dog population of 525,028 dogs. Journal of Veterinary Internal Medicine 30, 76-84.

Klein S., Peterson M. (2010a). Canine hypoadrenocorticism: Part I. Canine Veterinary Journal 51, 63-69.

Klein S., Peterson M. (2010b). Canine hypoadrenocorticism: Part II. Canine Veterinary Journal 51, 179-184.

Kintzer P., Peterson M. (1997). Treatment and long-term follow-up of 205 dogs with hypoadrenocorticism. Journal of Veterinary Medicine 11, 43-49.

Lathan P., Thompson A. (2018). Management of hypoadrenocorticism (Addison's disease) in dogs. Veterinary Medicine: Research and Reports 9, 1-10.

Meeking S. (2007). Treatment of acute adrenal insufficiency. Clinical Technical Small Animal Practice 22, 36-39.

Peterson M., Kintzer P., Kass P. (1996). Pretreatment clinical and laboratory findings in dogs with hypoadrenocorticism: 225 cases (1979-1993). Journal of the American Veterinary Medical Assocation 208, 85-91.

Reusch C. (2000). Hypoadrenocorticism. In: Ettinger S. and Feldman E. (editors). Textbook of Veterinary Internal Medicine. Fifth edition, Philadelphia, WB Saunders, p. 1488-1499.

Van Zyl M., Hyman W. (1994). Desoxycorticoserone pivalate in the management of canine primary hypoadrenocorticism. Journal of South African Veterinary Association 65, 125-129. 